\title{
Fuzzy Tuned PID Controller for Envisioned
}

\section{Agricultural Manipulator}

\author{
Satyam Paul ${ }^{1} \quad$ Ajay Arunachalam ${ }^{2} \quad$ Davood Khodadad ${ }^{3}$ \\ Henrik Andreasson ${ }^{2} \quad$ Olena Rubanenko ${ }^{4}$ \\ ${ }^{1}$ Department of Engineering Design and Mathematics, University of the West of England, Bristol BS16 1QY, UK \\ ${ }^{2}$ Centre for Applied Autonomous Sensor Systems (AASS), Orebro University, Orebro 70281, Sweden \\ ${ }^{3}$ Department of Applied Physics and Electronics, Umea University, Umea 90187, Sweden \\ ${ }^{4}$ Regional Innovational Center for Electrical Engineering, Faculty of Electrical Engineering, University of West Bohemia, \\ Pilsen 30100, Czech Republic
}

\begin{abstract}
The implementation of image-based phenotyping systems has become an important aspect of crop and plant science research which has shown tremendous growth over the years. Accurate determination of features using images requires stable imaging and very precise processing. By installing a camera on a mechanical arm driven by motor, the maintenance of accuracy and stability becomes non-trivial. As per the state-of-the-art, the issue of external camera shake incurred due to vibration is a great concern in capturing accurate images, which may be induced by the driving motor of the manipulator. So, there is a requirement for a stable active controller for sufficient vibration attenuation of the manipulator. However, there are very few reports in agricultural practices which use control algorithms. Although, many control strategies have been utilized to control the vibration in manipulators associated to various applications, no control strategy with validated stability has been provided to control the vibration in such envisioned agricultural manipulator with simple low-cost hardware devices with the compensation of non-linearities. So, in this work, the combination of proportional-integral-differential (PID) control with type-2 fuzzy logic (T2-F-PID) is implemented for vibration control. The validation of the controller stability using Lyapunov analysis is established. A torsional actuator (TA) is applied for mitigating torsional vibration, which is a new contribution in the area of agricultural manipulators. Also, to prove the effectiveness of the controller, the vibration attenuation results with T2-F-PID is compared with conventional PD/PID controllers, and a type-1 fuzzy PID (T1-F-PID) controller.
\end{abstract}

Keywords: Proportional-integral-differential (PID) controller, fuzzy logic, precision agriculture, vibration control, stability analysis, modular manipulator, agricultural robot, computer numerical control (CNC) farming.

Citation: S. Paul, A. Arunachalam, D. Khodadad, H. Andreasson, O. Rubanenko. Fuzzy tuned PID controller for envisioned agricultural manipulator. International Journal of Automation and Computing, vol.18, no.4, pp.568-580, 2021. http://doi.org/10.1007/s11633-021-1280-5

\section{Introduction}

\subsection{Precision agriculture system \& role of phenotyping}

Plants life plays a crucial role serving the conduit of energy into the biosphere, providing food, and shaping our environment. With the growth of new technologies plant science which has seen tremendous transformation, Ehrhardt and Frommer ${ }^{[1]}$ identify the role of technologies to address the challenges of new biology. But, with climate change being a major concern, outdoor farming is

\footnotetext{
Research Article

Manuscript received May 30, 2020; accepted January 22, 2021; published online April 13, 2021

Recommended by Associate Editor Victor Becerra

Colored figures are available in the online version at https://link. springer.com/journal/11633

(C) The author(s) 2021
}

more threatened than before, and further fertile land is now a limited resource globally. Approximately, a quarter of world $\mathrm{CO}_{2}$ emission comes from food production, and the global climate impact of agriculture is increasing dayby-day. The irony is that agriculture itself is the main contributor to climate change, which in-turn is severely affected by it. Scaling the food production to meet the future human demands, without compromising the quality, while also targeting sustainability, is non-trivial. One can just imagine the magnitude, like over the next 40 years, mankind must produce as much food as man has done in total over the past several 100 years. This brings the need for significant increase of the yield production. The United Nations estimates that the world population will rise from around 7.8 billion today to around 10 billion by 2050. The world will need lot more food, and the farmer community will face serious threats and challenges to keep up with demand with mounting pressure majorly due to climate change. So, this brings us to the need for 
food cultivation change, i.e., cyber agriculture/vertical farming/urban farming, while aiming sustainability over time. Certainly, the trend is towards indoor cultivation $^{[2-4]}$. But, then just remote indoor farming is not the ultimate solution. There is always a need for organized indoor cultivation for maximizing the harvest on a smaller compatible surface with optimized usage of resources, thereby preparing us today for the global needs of a better tomorrow. We discuss one such prototype (LOMAS++) (Fig. 1.) aimed for autonomous precision cultivation $^{[5]}$. A large pool of different sensors ( $\mathrm{pH}$ sensor, temperature sensor, environmental sensor, soil moisture sensor, soil temperature \& humidity sensor, lux sensor, array of MOX gas sensors, and quantum sensor) are interfaced as an Internet of things (IoT) facility ${ }^{[6]}$ monitoring the environmental conditions round-the-clock to maintain a controlled growing environment.

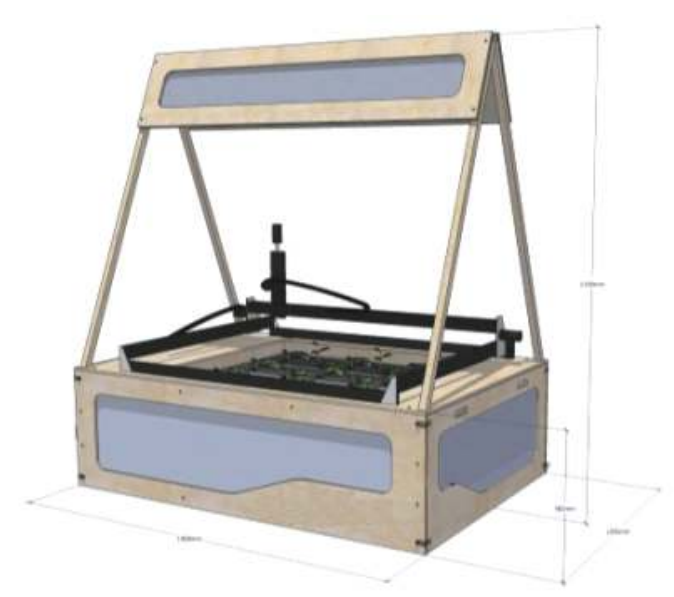

Fig. 1 Autonomous computer numerical control (CNC) cultivation test-bed $[7]$

The project is carried out in collaboration between Alfred Nobel Science Park, and AASS, Orebro University, Sweden. LOMAS ++ is an autonomous multifunctional farming cultivation bed, aimed for high quality indoor growth and monitoring of plants, with an aim to optimize the cultivation, while producing high quality yields.

It opens a new research dimension at Orebro University. Furthermore, it also provides a unique opportunity for students to use the prototype for academic purposes.

In general, plant phenotyping refers to the use of digital and non-invasive technologies to interpret the physical properties observed in plants. Examples include appearance, development, and reciprocal behavior, etc. Practise and understanding of agriculture has seen wide use of vision-based technologies. Plant phenotyping methods based on image processing have received much attention in recent years ${ }^{[7,8]}$. Plant phenotyping systems have been developed as a result of technology advancement, and the advent of various types of low-cost devices. The advantage of such approaches have key important aspects such as being non-destructive in nature, gaining high-throughput data continuously, etc. Everything from traditional to advanced traits, are obtained from images ${ }^{[9]}$ which provide crucial information revealing the plant health and stress status.

Agricultural robots are becoming a common part of modern farming methods. Nowadays, many operations of sorting, sorting and packing, spraying pests and controlling pests and weeds, detecting harvest time and existing diseases are done automatically with the intervention of agricultural robots ${ }^{[10]}$. Further, these robots have been used in different magnitudes from small scale to heavy duty applications ${ }^{[11]}$. The agricultural robots market is roughly expected to reach around 12 billion USD within the next 5 years. Articulated robotic arms have been widely used in most of these applications. The robot arm typically has different connections that can move at greater angles and move up or down. This is while the human arm can move (upwards) only in one direction by taking the reference of the straight arm. As an example, we can mention the articulated arm in [12].

The vulnerability of cameras mounted on such articulated robot arms is greater. Also, as a result of camera movement, camera shake and poor focus during exposure, the image loses its quality dramatically. Therefore, camera shake resulting from the running of the motors causes serious concerns in such image acquisitions, Oh et al. ${ }^{[13]}$ study the blur originating from the camera shake using the statistics of acquired images of the shaken camera in order to predict perceptual blur.

Industrial manipulators have been widely used in the past and are known as the robotic arm. Controlling and stabilizing such manipulations is still a topic of current researches. The robustness of proportional-integral-differential (PID) controllers against noise and other vibrationrelated parameters facilitates and justifies its application for practical control issues. Nguyen et al.[14] study the motion of a 6 -DOF (DOF represents degrees of freedom) robot, regardless of its cause such as force and torque. Control algorithms are widely used in many industries. One of them is structural vibration control. Leugering ${ }^{[15]}$ shows that a uniform exponential stability can be achieved by using a mechanically implemented damping device. But, then the active control becomes a non-trivial task, when it is non-linear in nature ${ }^{[16]}$. Etxebarria et al.[17] proposed a scheme that benefits from smooth function (instead of using the sign function) and uses a sliding-mode controller in order to alleviate the uncertainty and also disturbances for flexible link robotic manipulators. Neural networks have also been applied to various control problems. A neuro-controller to stabilize inverted arms is proposed in [18], where the validation of their method was done using Simulink simulations. In the work [19], a neural network (NN) controller is developed to minimize the vibration forces on the flexible robotic manipulator system associated with the input deadzone. A distinguishing model on the basis of nonlinear golden section adaptive control techniques is developed for vibra- 
tion minimization of a flexible Cartesian smart material manipulator which is initiated with the help of a ballscrew mechanism combined with an alternating current (AC) servomotor ${ }^{20]}$. A combined fuzzy+PI technique for active vibration attenuation of a flexible manipulator combined with lead zirconate titanate (PZT) patches was presented by Wei et al. ${ }^{21]}$ A dynamic modeling and an innovative vibration control strategy for a nonlinear threedimensional flexible manipulator was presented in [22]. Yavuz and Karagulle ${ }^{[23]}$ presented the vibration control of a single-link flexible composite manipulator using motion profiles. The trapezoidal and triangular velocity profiles are considered for the motion commands. Matsumori et al. ${ }^{24]}$ proposed an operator based nonlinear vibration attenuation technology utilizing a flexible arm in combination with shape memory alloy. The effectiveness of the proposed methodology is validated by simulations and experiments. An improvised quantum-inspired differential evolution termed as improved quantum-inspired differential evolution (MSIQDE) algorithm on the basis of Mexh wavelet function, standard normal distribution, adaptive quantum state update as well as quantum non-gate mutation is suggested by Deng et al.[25] for the avoidance of premature convergence and to upgrade global search capability. The abilities of the MSIQDE-DBN (DBN represents deep belief network) technique is verified by using the vibration data of rolling bearings from Case Western Reserve University, USA.

The concept of fuzzy logic has become extremely popular due to its non-linear mapping capability and can be used in various systems while maintaining robustness and simplicity. Therefore, due to the nature of robust and effective nonlinear mapping, fuzzy logic has found wide and increasing applications. Tong et al. ${ }^{[26]}$ provided an investigation on the adaptive fuzzy output feedback backstepping control design problem associated with uncertain strict-feedback nonlinear systems in the presence of unknown virtual as well as actual control gain functions with non measurable states. A novel adaptive fuzzy output feedback control methodology on the basis of backstepping design is illustrated by Tong and $\mathrm{Li}^{[27]}$ for a class of single-input and single-output (SISO) strict feedback nonlinear systems with unmeasured states, nonlinear uncertainties, unmodeled dynamics, as well as dynamical disturbances. The technique of fuzzy logic is implemented for the approximation of the nonlinear uncertainties. The state estimation is carried using an adaptive fuzzy state observer. Liu et al. ${ }^{[28]}$ proposed a fuzzy PID control technique in order to initiate the space manipulator and track the required trajectories in different gravity environments. The combination of fuzzy methodology with PID control is implemented to develop the novel methodology. PID controller parameters are tuned on line based on the fuzzy controller. An innovative control strategy of a two-wheeled machine with two-directions handling mechanism in combination with PID and PD-FLC (FLC represents fuzzy logic controller) algorithms was presen- ted by Goher and Fadlallah ${ }^{[29]}$. The use of an additional DOF embedded in type-2 fuzzy logic as a footprint of uncertainty makes it perform better than a type- 1 fuzzy logic system ${ }^{[30,31]}$. The main concept and the technical content of fuzzy logic type-2 is shown in [32]. Due to the fact that fuzzy logic type- 2 has better performance capacity than fuzzy logic type- 1 , it is then used as one of the efficient methods of compensating the uncertainty ${ }^{[33]}$. In the work of Paul et al. ${ }^{[34]}$, it was demonstrated that in the control of vibration of the structure, the type- 2 fuzzy $\mathrm{PD} / \mathrm{PID}$ controller performs better than the classical fuzzy PD/PID controller. Combining type-1 and type-2 fuzzy logic systems, an innovative method has been proposed and the performance of the proposed method is also demonstrated in pitch angle controlled wind energy systems. The results show that the type-2 fuzzy logic system offers better performance in comparison to type- 1 fuzzy logic systems ${ }^{[35]}$. There is another comparison between the performance of the two types which is implemented in the laser tracking system by Bai and Wang ${ }^{[36]}$. Sun et al. ${ }^{[37]}$ used the type-2 fuzzy model to control the overall stability of the multilateral tele-operation system, where the uncertainties are compensated with the fuzzymodel-based state observer.

\subsection{Motivation of this work}

As a part of the ongoing research project, a low-cost multi-spectral camera setup was designed as shown in Fig. 2, which is mounted over a mechanical manipulator arm as seen in Fig. 3. The manipulator arm under consideration has 2-DOF as highlighted in Fig. 4. Currently, the present setup (as seen in Fig. 3) is manual, where the camera field of view (FOV) is adjusted by the human operator according to the crop/plant species being inspected to get best view of the entire testbed. With vision to automate the present setup, where the arm will be motor driven, that aims to capture images, while either in continuous motion or discrete motion to get a closer view of

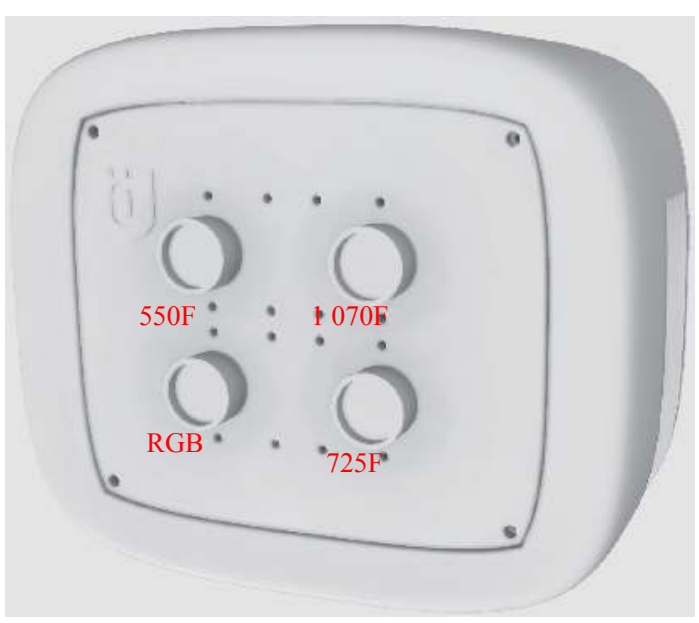

Fig. 2 Developed low-cost multispectral camera 


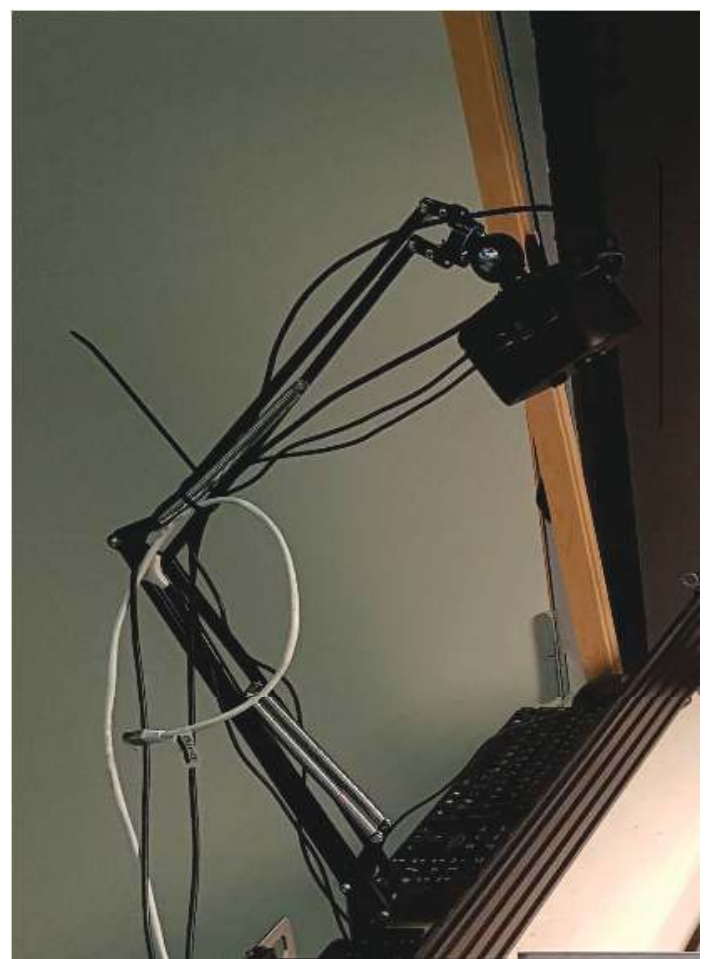

Fig. 3 Mounted setup

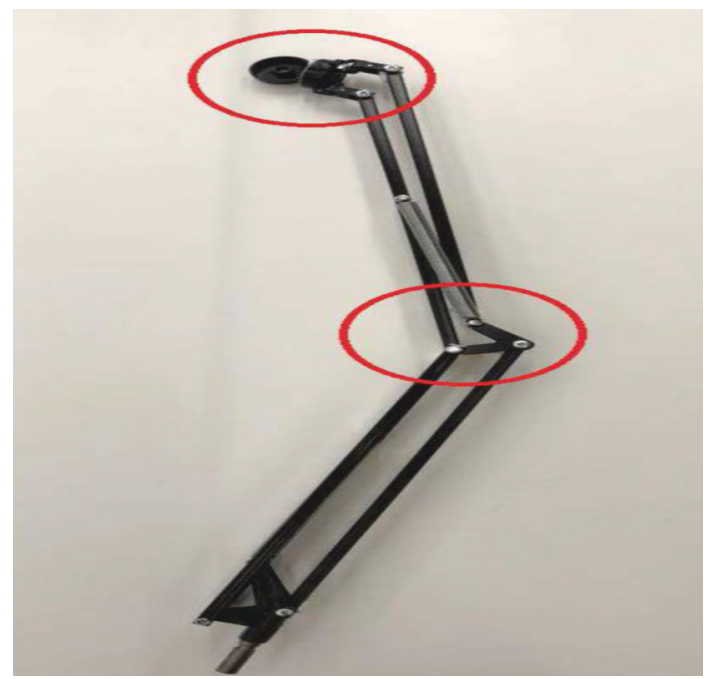

Fig. 4 Manipulator arm with 2-DOF being manually operated

the region of interest (ROI) during the operation demands stable vibration control.

To alleviate the near associated problems, we presumed with a theoretical analysis ${ }^{[38]}$ inspecting the application of PID controller in this direction.

While, on the contrary using any industrial state-ofthe-art robot arm like Panda 7-DOF from Franka Emika ${ }^{[39]}$ that is widely used by the robotics community will work perfectly for achieving an position-based visual servoing as the feedback information extracted from the vision sensor is used to control the motion of the robot. But, then the trade-off becomes the cost of acquiring one such commercial setup (Avg. 10500 USD). If the external camera block is shaken because of such movements, it will lead to poor image quality. Such vulnerabilities can generally be controlled offline or online ${ }^{[40]}$. In the past, researchers have focused on the first method, which required the use of sophisticated algorithms to perform various steps to create, enhance images, remove noise, and calibrate the camera offline. On the other hand, the second method for instant applications was and is more suitable. The work done in the past for online processing focused more on the use of sophisticated online algorithms. They were computationally overloaded. Therefore, given that our goal is to move towards mechanization of the current settings, we decided to study this issue in terms of hardware where control algorithms can be used to eliminate vibrations caused by the motor. For real-time applications or scenarios, an effective controller should be simplistic, robust, and resilient. Proportional derivative $(\mathrm{PD})$ control as well as PID control is implemented widely in different domains as it is the best control strategy, because it demonstrates its effectiveness without knowledge of the model.

While several control techniques were used to control the vibration in the manipulator in different applications, no validated stability control technique was given to control the vibration in such envisaged agricultural manipulators with simple low-cost hardware systems with nonlinearity compensation. So, this is the main motivation of this research. Based on the motivation, the main contributions of this work are: 1) The combination of PID control with type-2 fuzzy logic (T2-F-PID) is an innovative method, and first of its kind for this application for vibration control. 2) The controller stability for the agricultural application is validated using Lyapunov analysis. 3) The implementation of a torsional actuator (TA) for mitigating torsional vibration is a new contribution in the area of agricultural manipulators. Also, to prove the effectiveness of the controller, the vibration attenuation results with T2-F-PID is compared with conventional PD/PID controllers and a type-1 fuzzy PID (T1-F-PID) controller. The entire vibration control scheme is represented by Fig. 5 .

The paper is organized as follows. Section 2 describes the way the manipulator arm is controlled using the PID controller. The same is justified with mathematical analysis in Section 3. In Section 4, the proposed model is validated. Related works are enlisted in Section 5. And, finally, we conclude the paper in Section 6 .

\section{Type-2 fuzzy modeling of manipulator}

The polar moment of inertia of a direct current (DC) motor as shown in Fig. 6 is given by

$$
P_{t}=m_{m} r_{m}^{2}
$$

where $m_{m}$ signifies motor mass and $r_{m}$ signifies motor radius. Generated motor torque is represented as 


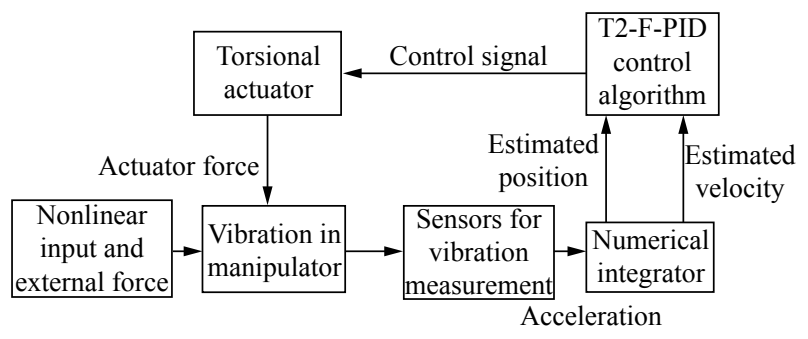

Fig. 5 Vibration control scheme of the manipulator
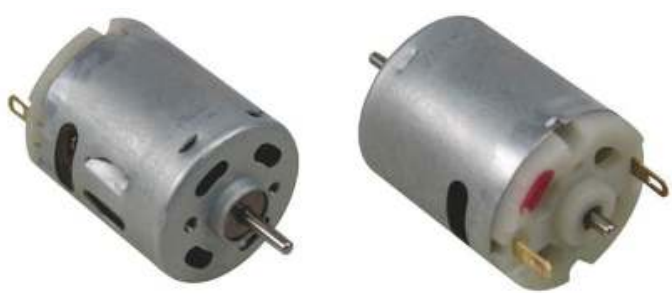

Fig. 6 Schematic of DC motor

$$
\tau=P_{t} \ddot{\theta}-F_{f}
$$

where the motor angular acceleration is represented by $\ddot{\theta}$ and $F_{f}$ is the frictional torque. The mathematical model of the manipulator having rotational motion due to the motor is

$$
P_{t} \ddot{\theta}+D_{\theta} \dot{\theta}+S \theta=f_{e}
$$

where $\theta$ is the angular position, $P_{t}$ is the polar moment of inertia, $D$ is the damping force, $S$ is the stiffness force vector, and $f_{e}$ is the external force on the manipulator. The manipulator with motor arrangements is shown in Fig. 7 .

Now let $u_{\theta}$ be the control force required to attenuate the torsional vibration. For minimization of vibration along the theta direction, a TA, is positioned at the physical center of the motor box arrangement which can be seen in Fig. 8. The TA is a rotating disc like structure combined with a DC motor.

The modeling equation of the manipulator (3) with the control force $u_{\theta}$ is

$$
P_{t} \ddot{\theta}+D_{\theta} \dot{\theta}+S \theta=f_{e}+u_{\theta}-F_{t a}
$$

where $F_{t a}$ is the damping and friction force vector associated with the torsional actuator. The torque $T_{\tau}$ generated by the torsional actuator is ${ }^{[41]}$

$$
T_{\tau}-F_{t a}=P_{t a}\left(\ddot{\theta}_{t a}+\ddot{\theta}\right)
$$

where $P_{t a}$ is the polar moment of inertia of the TA, $\ddot{\theta}_{t a}$ is the angular acceleration of the TA. The friction in the torsional actuator is

$$
F_{t a}=C \dot{\theta}+\left(F_{c}+F_{c s} \operatorname{sech}(H \dot{\theta})\right) \tanh (B \dot{\theta})
$$

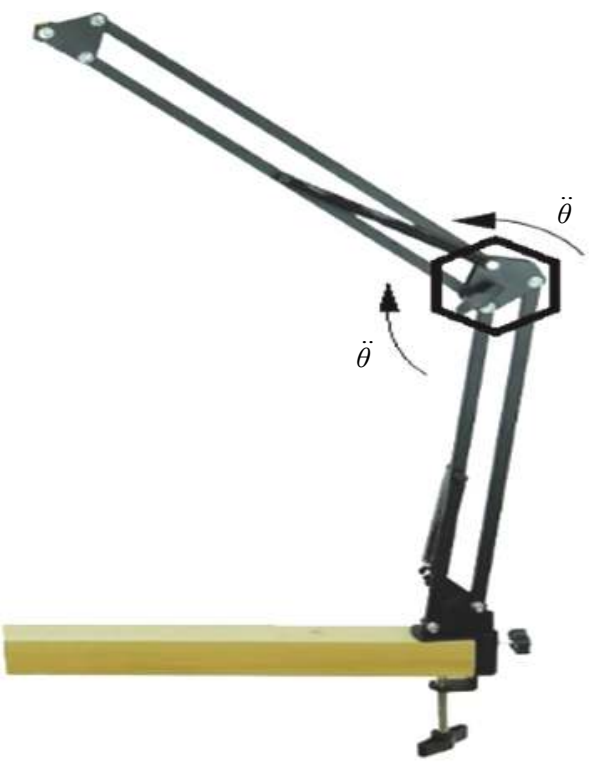

Fig. 7 Manipulator with motor arrangement

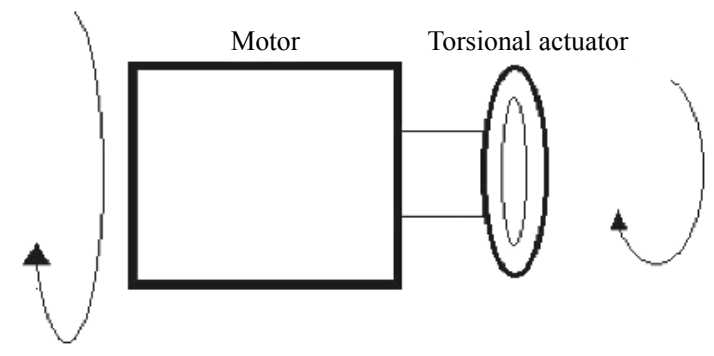

Fig. 8 Placement of TA

where $C$ and $F_{c}$ represent the torsional viscous friction coefficient and Coulomb friction torque respectively, $F_{c s}$ is the Striebeck effect component. Also, $H$ and $B$ are the dependent variables associated to $F_{c s}$ and $F_{c}$ respectively. The closed loop system (4) becomes

$P_{t} \ddot{\theta}+D_{\theta} \dot{\theta}+S \theta+C \dot{\theta}+\left(F_{c}+F_{c s} \operatorname{sech}(H \dot{\theta})\right) \tanh (B \dot{\theta})-f_{e}=u_{\theta}$.

Now in (5), $u_{\theta}$ is the control force to be fed to the torsional actuator for the vibration control which is equivalent to the torque force $P_{t a}\left(\ddot{\theta}_{t a}+\ddot{\theta}\right)$.

The term $C \dot{\theta}+\left(F_{c}+F_{c s} \operatorname{sech}(H \dot{\theta})\right) \tanh (B \dot{\theta})-f_{e}$ involves nonlinearity and has to be dealt with an effective manner. Now the nonlinear term can be expressed as follows:

$$
f_{\theta}=C \dot{\theta}+\left(F_{c}+F_{c s} \operatorname{sech}(H \dot{\theta})\right) \tanh (B \dot{\theta})-f_{e} .
$$

So, $(5)$ is

$$
m_{m} r_{m}^{2} \ddot{\theta}+D_{\theta} \dot{\theta}+S \theta+f_{\theta}=u_{\theta}
$$

For handling the nonlinearities, a type-2 fuzzy logic system is implemented. The type- 2 fuzzy sets can model 
uncertainties with less fuzzy rules and with greater ease.

The type-2 fuzzy sets has advantages over type-1 fuzzy sets as type-2 fuzzy involves less fuzzy rules in dealing with uncertainty effectively. Here $\tilde{T}$ denotes the type2 fuzzy set, where the characterization occurs by the

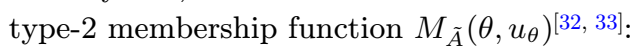

$$
\tilde{T}=\left\{\left(\theta, u_{\theta}\right), M_{\tilde{A}}\left(\theta, u_{\theta}\right) \mid \forall \theta \in \Theta, \forall u_{\theta} \in P_{\theta} \subseteq\left[\begin{array}{ll}
0 & 1
\end{array}\right]\right\}
$$

also, $0 \leq M_{\tilde{A}}\left(\theta, u_{\theta}\right) \leq 1$, where $P_{\theta}$ is considered as the primary membership of $\theta$. One of the crucial parts is the footprint of uncertainty (FOU) termed to be the union of associated primary memberships:

$$
\operatorname{FoU}(\tilde{T})=U_{\theta \in \Theta} P_{\theta}
$$

The IF-THEN rules implemented for type-2 fuzzy logic bears the same structure as the type- 1 fuzzy logic counterpart. This technique demands that the antecedents as well as the consequents are described by implementing interval type-2 Fuzzy sets. Hence, the $l$-th rule is $^{[42]}$

$$
\begin{aligned}
& R^{l}: \text { If }\left(\theta \text { is } \tilde{F}_{1}^{l}\right) \text { and }\left(\dot{\theta} \text { is } \tilde{F}_{2}^{l}\right) \\
& \text { Then }\left(f_{\theta} \text { is } \tilde{H}_{1}^{l}\right)
\end{aligned}
$$

where $\tilde{F}_{1}^{l}, \tilde{F}_{2}^{l}$, and $\tilde{H}_{1}^{l}$ represent fuzzy sets. For the implementation of the centroid methodology when combined with the center-of-sets type reduction technique, the fuzzy sets associated with the type-2 technique can be converted to an interval type-1 fuzzy set $\left[\begin{array}{ll}y_{l k}^{z} & y_{r k}^{z}\end{array}\right]$ by taking into consideration each rule of $z$. The deduced interval type-1 fuzzy set is represented as

$$
y_{l k}=\frac{\sum_{z=1}^{L} f_{l}^{z} y_{l k}^{z}}{\sum_{z=1}^{L} f_{l}^{z}}, y_{r k}=\frac{\sum_{z=1}^{L} f_{r}^{z} y_{r k}^{z}}{\sum_{z=1}^{L} f_{r}^{z}}
$$

where $f_{l}^{z} f_{r}^{z}$ denote the firing strengths linked to $y_{l k}^{z}$ and $y_{r k}^{z}$ of rule $i$. In the first instance, the extraction of the type-reduced set is achieved by utilizing the left most and the right most points $y_{l k}$ and $y_{r k}$. Once the above step is accomplished, the defuzzification occurs by utilizing interval set type average formula in order to extract the crisp output. The output associated with the fuzzy technique $\hat{f}_{\theta}$ can be expressed by using a singleton fuzzifier as ${ }^{[43]}$

$$
\begin{aligned}
& \hat{f}_{\theta}=\frac{y_{\text {right }}+y_{\text {left }}}{2} \\
& \hat{f}_{\theta}=\frac{1}{2}\left[\phi_{r}^{\mathrm{T}}\left(z_{\theta}\right) w_{r}\left(z_{\theta}\right)+\phi_{l}^{\mathrm{T}}\left(z_{\theta}\right) w_{l}\left(z_{\theta}\right)\right]
\end{aligned}
$$

where $z=[\theta \dot{\theta}]^{\mathrm{T}}$.

\section{Manipulator control}

PID controllers use the feedback technique approach, which has three interconnected actions:

$P$ : To increase the response velocity;

$D$ : For the purpose of damping;

$I$ : To achieve a required steady-state response.

A PID control is illustrated as

$$
u_{p i d}=-K_{p} e-K_{i} \int_{0}^{t} e \mathrm{~d} \tau-K_{d} \dot{e}
$$

where the gains of the PID controller are represented by $K_{p}, K_{i}$ and $K_{d}$, and they are positive definite in nature. $e$ is the error stated as $e=\theta-\theta^{d}, \dot{e}=\dot{\theta}-\dot{\theta}^{d}$. For the reference, $\theta^{d}=\dot{\theta}^{d}=0$. Therefore,

$$
e=\theta, \dot{e}=\dot{\theta}
$$

When the type-2 fuzzy technique is combined with the PID controller, then the outcome is

$$
\begin{aligned}
u_{\theta}= & -K_{p} \theta-K_{i} \int_{0}^{t} \theta \mathrm{d} \tau-K_{d} \dot{\theta}- \\
& \frac{1}{2} \phi_{r}^{\mathrm{T}}\left(z_{\theta}\right) w_{r}\left(z_{\theta}\right)-\frac{1}{2} \phi_{l}^{\mathrm{T}}\left(z_{\theta}\right) w_{l}\left(z_{\theta}\right) .
\end{aligned}
$$

The closed loop equation can be extracted from (7) and (13):

$$
\begin{gathered}
m_{m} r_{m}^{2} \ddot{\theta}+D_{\theta} \dot{\theta}+S \theta+f_{\theta}=-K_{p} \theta-K_{i} \int_{0}^{t} \theta \mathrm{d} \tau- \\
K_{d} \dot{\theta}-\frac{1}{2} \phi_{r}^{\mathrm{T}}\left(z_{\theta}\right) w_{r}\left(z_{\theta}\right)-\frac{1}{2} \phi_{l}^{\mathrm{T}}\left(z_{\theta}\right) w_{l}\left(z_{\theta}\right) .
\end{gathered}
$$

Let $K_{i} \int_{0}^{t} \theta \mathrm{d} \tau=I_{\theta}$, then

$$
\begin{aligned}
& \dot{I}_{\theta}=K_{i} \theta \\
& \frac{\mathrm{d}}{\mathrm{d} t}(\theta)=-\left(m_{m} r_{m}^{2}\right)^{-1}\left[D_{\theta} \dot{\theta}+S \theta+f_{\theta}+K_{p} \theta+K_{d} \theta+\right. \\
& \left.\quad I_{\theta}+\frac{1}{2} \phi_{r}^{\mathrm{T}}\left(z_{\theta}\right) w_{r}\left(z_{\theta}\right)+\frac{1}{2} \phi_{l}^{\mathrm{T}}\left(z_{\theta}\right) w_{l}\left(z_{\theta}\right)\right]
\end{aligned}
$$

where $I_{\theta}$ is the auxiliary variable. In matrix form, $(15)$ is

$$
\frac{\mathrm{d}}{\mathrm{d} t}\left[\begin{array}{c}
I_{\theta} \\
\theta \\
\dot{\theta}
\end{array}\right]=\left[\begin{array}{c}
K_{i x} \theta \\
\dot{\theta} \\
-\left(m_{m} r_{m}^{2}\right)^{-1}\left[D_{\theta} \dot{\theta}+S \theta+f_{\theta}+u_{\theta}\right]
\end{array}\right] .
$$

From (14), it is justified that the origin is not at the equilibrium and is in the format $\left[\begin{array}{lll}\theta & \dot{\theta} & I_{\theta}\end{array}\right]=\left[\begin{array}{lll}\theta & \dot{\theta} & I_{\theta}^{*}\end{array}\right]$. Since at equilibrium point $\theta=0, \dot{\theta}=0$, then the equilibrium is

$$
\left[0,0, \lambda_{\theta}(0,0)\right]
$$

where $I_{\theta}^{*}=I_{\theta}-\lambda_{\theta}(0,0)$. Using the Stone-Weierstrass theorem, $f_{\theta}$ can be estimated as 


$$
f_{\theta}=\frac{1}{2} \phi_{r}^{\mathrm{T}}\left(z_{\theta}\right) w_{r}^{*}\left(z_{\theta}\right)+\frac{1}{2} \phi_{l}^{\mathrm{T}}\left(z_{\theta}\right) w_{l}^{*}\left(z_{\theta}\right)+\lambda_{\theta}
$$

where the model error is represented by $\lambda_{\theta}$ and

$$
\begin{aligned}
& \tilde{w}_{r}\left(z_{\theta}\right)=-\left[w_{r}\left(z_{\theta}\right)+w_{r}^{*}\left(z_{\theta}\right)\right] \\
& \tilde{w}_{l}\left(z_{\theta}\right)=-\left[w_{l}\left(z_{\theta}\right)+w_{l}^{*}\left(z_{\theta}\right)\right] .
\end{aligned}
$$

Using (14) and (17)

$$
\begin{aligned}
& m_{m} r_{m}^{2} \ddot{\theta}+D_{\theta} \dot{\theta}+S \theta+\frac{1}{2} \phi_{r}^{\mathrm{T}}\left(z_{\theta}\right) w_{r}^{*}\left(z_{\theta}\right)+ \\
& \frac{1}{2} \phi_{l}^{\mathrm{T}}\left(z_{\theta}\right) w_{l}^{*}\left(z_{\theta}\right)+\lambda_{\theta}=-K_{p} \theta-I_{\theta}+I_{e q}(0,0)- \\
& K_{d} \dot{\theta}-\frac{1}{2} \phi_{r}^{\mathrm{T}}\left(z_{\theta}\right) w_{r}\left(z_{\theta}\right)-\frac{1}{2} \phi_{l}^{\mathrm{T}}\left(z_{\theta}\right) w_{l}\left(z_{\theta}\right) .
\end{aligned}
$$

The lower bound of $\lambda_{\theta}$ which is nonlinear in nature is illustrated as

$$
\begin{aligned}
\int_{0}^{t} \lambda_{\theta} \mathrm{d} \theta= & \int_{0}^{t} F_{\theta t a} \mathrm{~d} \theta-\int_{0}^{t} f_{\theta e} \mathrm{~d} \theta-\frac{1}{2} \int_{0}^{t} \phi_{r}^{\mathrm{T}}\left(z_{\theta}\right) w_{r}\left(z_{\theta}\right) \mathrm{d} \theta+ \\
& \frac{1}{2} \int_{0}^{t} \phi_{l}^{\mathrm{T}}\left(z_{\theta}\right) w_{l}\left(z_{\theta}\right) \mathrm{d} \theta
\end{aligned}
$$

The lower bounds are $\int_{0}^{t} F_{\theta t a} \mathrm{~d} \theta=-\bar{F}_{\theta t a} \theta t a$ and $\int_{0}^{t} f_{\theta e} \mathrm{~d} \theta=-\bar{f}_{\theta e}$. Also, the Gaussian functions are represented by $\phi_{r}^{\mathrm{T}}\left(z_{\theta}\right)$ and $\phi_{l}^{\mathrm{T}}\left(z_{\theta}\right)$, so

$$
\begin{aligned}
& \frac{1}{2}\left[\int_{0}^{t} \phi_{r}^{\mathrm{T}}\left(z_{\theta}\right) w_{r}\left(z_{\theta}\right) \mathrm{d} \theta+\int_{0}^{t} \phi_{l}^{\mathrm{T}}\left(z_{\theta}\right) w_{l}\left(z_{\theta}\right) \mathrm{d} \theta\right]= \\
& \frac{\sqrt{\pi}}{4} \operatorname{erf}\left(z_{\theta}\right)\left[w_{r}\left(z_{\theta}\right)+w_{l}\left(z_{\theta}\right)\right] .
\end{aligned}
$$

Now the modeling error $\lambda_{\theta}$ is Lipschitz over $a, b$ such that:

$$
\left\|\lambda_{\theta}(a)-\lambda_{\theta}(b)\right\| \leq L_{\theta}\|a-b\|
$$

where $L_{\theta}$ is the Lipschitz constant. So, using (20) and (22):

$$
L_{\theta}=-\bar{F}_{\theta t a}-\bar{f}_{\theta e}-\frac{\sqrt{\pi}}{4} \operatorname{erf}\left(z_{\theta}\right)\left[w_{r}\left(z_{\theta}\right)+w_{l}\left(z_{\theta}\right)\right]
$$

Also to prove the stability of the T2-F-PID control, the property of the eigen value should be considered and stated as

$$
0<\lambda_{m}\left(m_{m} r_{m}^{2}\right) \leq r_{m}^{2}\left\|m_{m}\right\| \leq \lambda_{M}\left(m_{m} r_{m}^{2}\right) \leq r_{m}^{2} \bar{m}
$$

where the min and max eigenvalues of the matrix $m_{m}$ are represented by $\lambda_{m}\left(m_{m}\right)$ and $\lambda_{M}\left(m_{m}\right)$ respectively, also $r_{m}^{2} \bar{m}>0$ is the upper bound.

The following theorem gives the stability analysis of T2-F-PID controller (13).

Theorem 1. If the T2-F-PID controller (13) is used to control a closed loop manipulator system (4), then the asymptotic stability of the system is assured when the fuzzy laws are

$$
\begin{aligned}
\frac{\mathrm{d}}{\mathrm{d} \theta} \tilde{w}_{r}\left(z_{\theta}\right) & =-\frac{\eta_{1} r_{m}^{2}}{t_{1}}\left[\left(\dot{\theta}+\rho_{\theta} \theta\right)^{\mathrm{T}} \phi_{r}^{\mathrm{T}}\left(z_{\theta}\right)\right]^{\mathrm{T}} \\
\frac{\mathrm{d}}{\mathrm{d} \theta} \tilde{w}_{l}\left(z_{\theta}\right) & =-\frac{\eta_{2} r_{m}^{2}}{t_{2}}\left[\left(\dot{\theta}+\rho_{\theta} \theta\right)^{\mathrm{T}} \phi_{l}^{\mathrm{T}}\left(z_{\theta}\right)\right]^{\mathrm{T}}
\end{aligned}
$$

and the PID control gains are within the range as

$$
\begin{aligned}
& \lambda_{m}\left(K_{p}\right) \geq \frac{2}{\rho_{\theta}} \lambda_{M}\left(K_{i}\right)+\lambda_{M}\left(D_{\theta}\right)+L_{\theta}+\frac{2}{\rho_{\theta}} \Gamma_{M} \\
& \lambda_{M}\left(K_{i}\right) \leq \frac{\sqrt{\lambda_{m}\left(K_{p}\right)^{3}} \sqrt{\lambda_{m}\left(m_{m}\right)}}{10.4\left(\lambda_{M}\left(m_{m}\right)\right)} \\
& \lambda_{m}\left(K_{d}\right) \geq \frac{\rho_{\theta}}{2} \lambda_{M}\left(m_{m}\right)-\Gamma_{M}-\frac{\rho_{\theta}}{2} \lambda_{M}\left(D_{\theta}\right)-\lambda_{m}\left(D_{\theta}\right)
\end{aligned}
$$

where $\lambda_{m}$ and $\lambda_{M}$ are the minimum and maximum eigenvalues of the matrices.

Proof. Here, the Lyapunov candidate is defined as

$$
\begin{aligned}
V_{\theta}= & \frac{1}{4} \dot{\theta}^{\mathrm{T}} m_{m} \dot{\theta}+\frac{1}{4} \theta^{\mathrm{T}} K_{p} \theta+\frac{\rho_{\theta}}{4} I_{\theta}^{* \mathrm{~T}} K_{i}^{-1} I_{\theta}^{*}+\theta^{\mathrm{T}} I_{\theta}^{*}+ \\
& \frac{\rho_{\theta}}{4} \theta^{\mathrm{T}} m_{m} \dot{\theta}+\frac{\rho_{\theta}}{4} \theta^{\mathrm{T}} K_{d} \theta+\frac{1}{2 r_{m}^{2}} \int_{0}^{t} \lambda_{\theta} \mathrm{d} \theta-L_{\theta}+ \\
& \frac{t_{1}}{8 \eta_{1}}\left[\tilde{w}_{r}^{\mathrm{T}}\left(z_{\theta}\right) \tilde{w}_{r}\left(z_{\theta}\right)\right]+\frac{t_{2}}{8 \eta_{2}}\left[\tilde{w}_{l}^{\mathrm{T}}\left(z_{\theta}\right) \tilde{w}_{l}\left(z_{\theta}\right)\right] .
\end{aligned}
$$

It is obvious that $V_{\theta}(0)=0$. For validating $V_{\theta} \geq 0, V_{\theta}$ is distributed in three separate parts in such a manner that $V_{\theta}=V_{\theta 1}+V_{\theta 2}+V_{\theta 3}$,

$$
\begin{gathered}
V_{\theta 1}=\frac{1}{12} \theta^{\mathrm{T}} K_{p} \theta+\frac{\rho_{\theta}}{4} \theta^{\mathrm{T}} K_{d} \theta+\int_{0}^{t} \lambda_{\theta} \mathrm{d} \theta-L_{\theta}+ \\
\frac{t_{1}}{8 \eta_{1}}\left[\tilde{w}_{r}^{\mathrm{T}}\left(z_{\theta} \tilde{w}_{r}\left(z_{\theta}\right)\right]+\frac{t_{2}}{8 \eta_{2}}\left[\tilde{w}_{l}^{\mathrm{T}}\left(z_{\theta}\right) \tilde{w}_{l}\left(z_{\theta}\right)\right] \geq 0 .\right.
\end{gathered}
$$

The above condition is true because $K_{p}>0, K_{d}>0$ and $\left\|\tilde{w}_{r}\left(z_{\theta}\right)\right\|^{2}>0,\left\|\tilde{w}_{l}\left(z_{\theta}\right)\right\|^{2}>0$.

$$
\begin{aligned}
V_{\theta 2} & =\frac{1}{12} \theta^{\mathrm{T}} K_{p} \theta+\frac{\rho_{\theta}}{4} I_{\theta}^{* \mathrm{~T}} K_{i}^{-1} I_{\theta}^{*}+\theta^{\mathrm{T}} I_{\theta}^{*} \geq \\
\frac{1}{4} & {\left[\frac{1}{3} \lambda_{m}\left(K_{p}\right)\|\theta\|^{2}++\rho_{\theta} \lambda_{m}\left(K_{i}^{-1}\right)\left\|I_{\theta}^{*}\right\|^{2}-4\|\theta\|\left\|I_{\theta}^{*}\right\|\right] . }
\end{aligned}
$$

$$
\begin{aligned}
& \text { When } \rho_{\theta} \geq \frac{12}{\lambda_{m}\left(K_{p}\right) \lambda_{m}\left(K_{i}^{-1}\right)} \\
& V_{\theta 2} \geq \frac{1}{4}\left(\sqrt{\frac{\lambda_{m}\left(K_{p}\right)}{3}}\|\theta\|-2 \sqrt{\frac{3}{\lambda_{m}\left(K_{p}\right)}}\left\|I_{\theta}^{*}\right\|\right)^{2} \geq 0
\end{aligned}
$$

and

$$
V_{\theta 3}=\frac{1}{12} \theta^{\mathrm{T}} K_{p} \theta+\frac{1}{4} \dot{\theta}^{\mathrm{T}} m_{m} \dot{\theta}+\frac{\rho_{\theta}}{4} \theta^{\mathrm{T}} m_{m} \dot{\theta}
$$

Utilizing the inequality equations, 
$\Delta^{\mathrm{T}} \Gamma \Omega \geq\|\Delta\|\|\Gamma \Omega\| \geq\|\Delta\|\|\Gamma\|\|\Omega\| \geq \lambda_{M}(\Gamma)\|\Delta\|\|\Omega\|$

Using (30),

$$
\begin{aligned}
V_{\theta 3} \geq & \frac{1}{4}\left(\frac{1}{3} \lambda_{m}\left(K_{p}\right)\|\theta\|^{2}+\lambda_{m}\left(m_{m}\right)\|\dot{\theta}\|^{2}+\right. \\
& \left.\rho_{\theta} \lambda_{M}\left(m_{m}\right)\|\theta\|\|\dot{\theta}\|\right)
\end{aligned}
$$

since

$$
\begin{aligned}
& \rho_{\theta} \leq \frac{2}{\sqrt{3}} \frac{\sqrt{\lambda_{m}\left(m_{m}\right) \lambda_{m}\left(K_{p}\right)}}{\lambda_{M}\left(m_{m}\right)} \\
& V_{\theta 3} \geq \frac{1}{4}\left(\sqrt{\frac{\lambda_{m}\left(K_{p}\right)}{3}}\|\theta\|+\sqrt{\lambda_{m}\left(m_{m}\right)}\|\dot{\theta}\|\right)^{2} \geq 0 .
\end{aligned}
$$

Using (27), (29) and (33), $V_{\theta}=V_{\theta 1}+V_{\theta 2}+V_{\theta 3} \geq 0$. Now we have

$$
\frac{2}{\sqrt{3}} \frac{\sqrt{\lambda_{m}\left(m_{m}\right) \lambda_{m}\left(K_{p}\right)}}{\lambda_{M}\left(m_{m}\right)} \geq \mu_{x} \geq \frac{12}{\lambda_{m}\left(K_{p}\right) \lambda_{m}\left(K_{i}^{-1}\right)} .
$$

Using the relation $\lambda_{m}\left(K_{i}^{-1}\right)=\frac{1}{\lambda_{M}\left(K_{i}\right)}$ in $(34)$,

$$
\begin{aligned}
& \frac{\sqrt{\lambda_{m}\left(m_{m}\right)}}{\lambda_{M}\left(m_{m}\right)} \geq \frac{6 \sqrt{3} \lambda_{M}\left(K_{i}\right)}{\sqrt{\lambda_{m}\left(K_{p}\right)} \lambda_{m}\left(K_{p}\right)} \\
& \lambda_{M}\left(K_{i}\right) \leq \frac{\sqrt{\lambda_{m}\left(K_{p}\right)^{3}} \sqrt{\lambda_{m}\left(m_{m}\right)}}{10.4\left(\lambda_{M}\left(m_{m}\right)\right)} .
\end{aligned}
$$

The derivative of $(26)$ is

$$
\begin{aligned}
\dot{V}_{\theta}= & \frac{1}{2 r_{m}^{2}} \dot{\theta}^{\mathrm{T}}\left[-D_{\theta} \dot{\theta}-S \theta-\frac{1}{2} \phi_{r}^{\mathrm{T}}\left(z_{\theta}\right) w_{r}^{*}\left(z_{\theta}\right)-\right. \\
& \frac{1}{2} \phi_{l}^{\mathrm{T}}\left(z_{\theta}\right) w_{l}^{*}\left(z_{\theta}\right)-\lambda_{\theta}-K_{p} \theta-I_{\theta}+I_{e q}(0,0)-K_{d} \dot{\theta}- \\
& \left.\frac{1}{2} \phi_{r}^{\mathrm{T}}\left(z_{\theta}\right) w_{r}\left(z_{\theta}\right)-\frac{1}{2} \phi_{l}^{\mathrm{T}}\left(z_{\theta}\right) w_{l}\left(z_{\theta}\right)\right]+\frac{1}{2} \dot{\theta}^{\mathrm{T}} K_{p} \theta+ \\
& \frac{\rho_{\theta}}{2} \frac{\mathrm{d}}{\mathrm{d} \theta} I_{\theta}^{*^{\mathrm{T}}} K_{i}^{-1} I_{\theta}^{*}+\theta^{\mathrm{T}} \frac{\mathrm{d}}{\mathrm{d} \theta} I_{\theta}^{*}+\dot{\theta}^{\mathrm{T}} I_{\theta}^{*}+\frac{1}{2 r_{m}^{2}} \dot{\theta}^{\mathrm{T}} \lambda_{\theta}+ \\
& \frac{\rho_{\theta}}{2 r_{m}^{2}} \theta^{\mathrm{T}}\left[-D_{\theta} \dot{\theta}-S \theta-\frac{1}{2} \phi_{r}^{\mathrm{T}}\left(z_{\theta}\right) w_{r}^{*}\left(z_{\theta}\right)-\right. \\
& \frac{1}{2} \phi_{l}^{\mathrm{T}}\left(z_{\theta}\right) w_{l}^{*}\left(z_{\theta}\right)-\lambda_{\theta}-K_{p} \theta-I_{\theta}+I_{e q}(0,0)- \\
& \left.K_{d} \dot{\theta}-\frac{1}{2} \phi_{r}^{\mathrm{T}}\left(z_{\theta}\right) w_{r}\left(z_{\theta}\right)-\frac{1}{2} \phi_{l}^{\mathrm{T}}\left(z_{\theta}\right) w_{l}\left(z_{\theta}\right)\right]+ \\
& \frac{\rho_{\theta}}{2} \dot{\theta}^{\mathrm{T}} m_{m} \dot{\theta}+\frac{\rho_{\theta}}{2} \dot{\theta}^{\mathrm{T}} K_{d} \theta+\frac{t_{1}}{4 \eta_{1}}\left[\frac{\mathrm{d}}{\mathrm{d} \theta} \tilde{w}_{r}^{\mathrm{T}}\left(z_{\theta}\right) \tilde{w}_{r}\left(z_{\theta}\right)\right]+ \\
& \frac{t_{2}}{4 \eta_{2}}\left[\frac{\mathrm{d}}{\mathrm{d} \theta} \tilde{w}_{l}^{\mathrm{T}}\left(z_{\theta}\right) \tilde{w}_{l}\left(z_{\theta}\right)\right] .
\end{aligned}
$$

Let us consider $\tilde{w}_{r}\left(z_{\theta}\right)=-\left[w_{r}\left(z_{\theta}\right)+w_{r}^{*}\left(z_{\theta}\right)\right], \tilde{w}_{l}\left(z_{\theta}\right)=$ $-\left[w_{l}\left(z_{\theta}\right)+w_{l}^{*}\left(z_{\theta}\right)\right]$. Also considering the fuzzy methodo- logy, if the updated laws are selected in the manner mentioned below:

$$
\begin{aligned}
\frac{\mathrm{d}}{\mathrm{d} \theta} \tilde{w}_{r}\left(z_{\theta}\right) & =-\frac{\eta_{1} r_{m}^{2}}{t_{1}}\left[\left(\dot{\theta}+\rho_{\theta} \theta\right)^{\mathrm{T}} \phi_{r}^{\mathrm{T}}\left(z_{\theta}\right)\right]^{\mathrm{T}} \\
\frac{\mathrm{d}}{\mathrm{d} \theta} \tilde{w}_{l}\left(z_{\theta}\right) & =-\frac{\eta_{2} r_{m}^{2}}{t_{2}}\left[\left(\dot{\theta}+\rho_{\theta} \theta\right)^{\mathrm{T}} \phi_{l}^{\mathrm{T}}\left(z_{\theta}\right)\right]^{\mathrm{T}}
\end{aligned}
$$

then (36) becomes

$$
\begin{aligned}
\dot{V}_{\theta}= & \frac{1}{2 r_{m}^{2}} \dot{\theta}^{\mathrm{T}}\left[-D_{\theta} \dot{\theta}-S \theta-K_{p} \theta-K_{d} \dot{\theta}-I_{\theta}+I_{e q}(0,0)\right]+ \\
& \frac{1}{2} \dot{\theta}^{\mathrm{T}} K_{p} \theta+\frac{\rho_{\theta}}{2} \frac{\mathrm{d}}{\mathrm{d} \theta} I_{\theta}^{*^{\mathrm{T}}} K_{i}^{-1} I_{\theta}^{*}+\theta^{\mathrm{T}} \frac{\mathrm{d}}{\mathrm{d} \theta} I_{\theta}^{*}++\dot{\theta}^{\mathrm{T}} I_{\theta}^{*}+ \\
& \frac{\rho_{\theta}}{2} \dot{\theta}^{\mathrm{T}} m_{m} \dot{\theta}+\frac{\rho_{\theta}}{2} \dot{\theta}^{\mathrm{T}} K_{d} \theta+\frac{\rho_{\theta}}{2 r_{m}^{2}} \theta^{\mathrm{T}}\left[-D_{\theta} \dot{\theta}-S \theta-\right. \\
& \left.\lambda_{\theta}-K_{p} \theta-K_{d} \dot{\theta}-I_{\theta}+I_{e q}(0,0)\right] .
\end{aligned}
$$

As $\quad I_{\theta}^{*}=I_{\theta}-\lambda_{\theta}(0,0) \quad$ and $\quad \frac{\mathrm{d}}{\mathrm{d} \theta} I_{\theta}^{*}=K_{i} \theta$, $\frac{\mathrm{d}}{\mathrm{d} \theta} I_{\theta}^{*^{\mathrm{T}}} K_{i}^{-1} I_{\theta}^{*}=\theta^{\mathrm{T}} I_{\theta}^{*}, \theta^{\mathrm{T}} \frac{\mathrm{d}}{\mathrm{d} \theta} I_{\theta}^{*}=\theta^{\mathrm{T}} K_{i} \theta$. Also, $r_{m} \approx 1$.

$$
\begin{aligned}
\dot{V}_{\theta}= & -\frac{1}{2} \dot{\theta}^{\mathrm{T}}\left[D_{\theta} \dot{\theta}+S \theta+K_{d} \dot{\theta}-\frac{\rho_{\theta}}{2} m_{m} \dot{\theta}\right]- \\
& \frac{\rho_{\theta}}{2} \theta^{\mathrm{T}}\left[D_{\theta} \dot{\theta}+S \theta+K_{p} \theta\right]+\theta^{\mathrm{T}} K_{i} \theta+ \\
& \frac{\rho_{\theta}}{2} \theta^{\mathrm{T}}\left[I_{e q}(0,0)-I_{\theta}\right] .
\end{aligned}
$$

Using the Lipschitz condition (22) and the property $N^{\mathrm{T}} D+D^{\mathrm{T}} N \leq N^{\mathrm{T}} \Phi N+D^{\mathrm{T}} \Phi^{-1} D$,

$$
\begin{aligned}
& \frac{\rho_{\theta}}{2} \theta^{\mathrm{T}}\left[I_{e q}(0,0)-I_{\theta}\right] \leq \frac{\rho_{\theta}}{2} L_{\theta}\|\theta\|^{2}- \\
& \frac{\rho_{\theta}}{2} \theta^{\mathrm{T}} D_{\theta} \dot{\theta} \leq \frac{\rho_{\theta}}{2} \lambda_{M}\left(D_{\theta}\right)\left(\theta^{\mathrm{T}} \theta+\dot{\theta}^{\mathrm{T}} \dot{\theta}\right)- \\
& \frac{\rho_{\theta}}{2} \dot{\theta}^{\mathrm{T}} S \theta \leq \Gamma_{M}\left(\theta^{\mathrm{T}} \theta+\dot{\theta}^{\mathrm{T}} \dot{\theta}\right), \quad \Gamma_{M} \leq \lambda_{M}(S) .
\end{aligned}
$$

Using (23) and (39) in (38):

$$
\begin{aligned}
\dot{V}_{\theta} \leq & -\dot{\theta}^{\mathrm{T}}\left[\lambda_{m}\left(D_{\theta}\right)+\lambda_{m}\left(K_{d}\right)-\frac{\rho_{\theta}}{2} \lambda_{M}\left(m_{m}\right)-\Gamma_{M-}-\right. \\
& \left.\frac{\rho_{\theta}}{2} \lambda_{M}\left(D_{\theta}\right)\right] \dot{\theta}-\theta^{\mathrm{T}}\left[\frac{\rho_{\theta}}{2} \lambda_{m}\left(K_{p}\right)+\frac{\rho_{\theta}}{2} \lambda_{m}(S)-\right. \\
& \left.\lambda_{M}\left(K_{i}\right)-\frac{\rho_{\theta}}{2} \lambda_{M}\left(D_{\theta}\right)-\frac{\rho_{\theta}}{2} L_{\theta}-\Gamma_{M}\right] \theta
\end{aligned}
$$

The stability conditions are justified (40), if

1) $\lambda_{m}\left(D_{\theta}\right)+\lambda_{m}\left(K_{d}\right) \geq \frac{\rho_{\theta}}{2} \lambda_{M}\left(m_{m}\right)-\Gamma_{M}-\frac{\rho_{\theta}}{2} \lambda_{M}\left(D_{\theta}\right)$

2) $\frac{\rho_{\theta}}{2}\left[\lambda_{m}\left(K_{p}\right)+\lambda_{m}(S)\right] \geq \lambda_{M}\left(K_{i}\right)+\frac{\rho_{\theta}}{2} \lambda_{M}\left(D_{\theta}\right)+$

$$
\frac{\rho_{\theta}}{2} L_{\theta}+\Gamma_{M} \text {. }
$$

From the stability conditions and (35), the ranges of gains are 


$$
\begin{aligned}
& \lambda_{m}\left(K_{p}\right) \geq \frac{2}{\rho_{\theta}} \lambda_{M}\left(K_{i}\right)+\lambda_{M}\left(D_{\theta}\right)+L_{\theta}+\frac{2}{\rho_{\theta}} \Gamma_{M} \\
& \lambda_{m}\left(K_{d}\right) \geq \frac{\rho_{\theta}}{2} \lambda_{M}\left(m_{m}\right)-\Gamma_{M}-\frac{\rho_{\theta}}{2} \lambda_{M}\left(D_{\theta}\right)-\lambda_{m}\left(D_{\theta}\right) \\
& \lambda_{M}\left(K_{i}\right) \leq \frac{\sqrt{\lambda_{m}\left(K_{p}\right)^{3}} \sqrt{\lambda_{m}\left(m_{m}\right)}}{10.4\left(\lambda_{M}\left(m_{m}\right)\right)}
\end{aligned}
$$

So the controller will generate stable control forces when the gains are selected from the stability zones as represented by (43).

\section{Analysis and validation}

Manipulator parameters are obtained from [24, 44] in order to confirm the capability and performance of the proposed fuzzy PID controller. These parameters are used to simulate the manipulator process and to achieve the motion with vibration control. Such parameters are used to model the process of the manipulator. They are also used to obtain the motion with a controlled vibration. The various parameters linked to the system are illustrated in Table 1.

Table 1

\begin{tabular}{cc}
\hline Simulation parameters & Values \\
\hline Mass $\left(m_{m}, \mathrm{~kg}\right)$ & 2 \\
Spring constant $(S, \mathrm{~N} / \mathrm{m})$ & $5 \times 10^{3}$ \\
Damping constant $\left(D_{\theta}, \mathrm{Ns} / \mathrm{m}\right)$ & 9 \\
TA friction coefficient $(\mathrm{Nm} / \mathrm{rad})$ & 0.95 \\
TA motor torque constant $(\mathrm{Nm} / \mathrm{V})$ & 0.06 \\
TA encoder gain $(\mathrm{V} / \mathrm{rad})$ & 0.3979 \\
\hline
\end{tabular}

The input nonlinearity for the purpose of the simulation is the Coulomb friction ${ }^{[45]}$ associated with the manipulator's torsional motion. The friction of the Coulomb is of a nonlinear type:

$$
F C_{\text {sim }}=\alpha_{0} \operatorname{sgn}(\dot{\theta})+\alpha_{1} \mathrm{e}^{-\alpha_{2}|\dot{\theta}|} \operatorname{sgn}(\dot{\theta})
$$

where $\alpha_{0}, \alpha_{1}, \alpha_{2}$ are the friction constants and $\dot{\theta}$ is the velocity of the manipulator. The simulation of the manipulator is done using the Matlab/Simulink platform. The Simulink program is used to create different simulations to show the adequate vibration attenuation of the agricultural manipulator can be accomplished by using the T2-F-PID controller. The vibration attenuation capabilities of the indicated controller are contrasted with the basic PD/PID and T1-F-PID controllers to check the efficiency of the T2-F-PID controller. A PD controller is of the form:

$$
u_{p d}=-K_{p} e-K_{d} \dot{e}
$$

where $K_{p}$ and $K_{d}$ are the gains as stated earlier. The error $e$ is illustrated as $\mathrm{e}=\theta-\theta^{d}, \dot{\mathrm{e}}=\dot{\theta}-\dot{\theta}^{d}$. For the reference, $\theta^{d}=\dot{\theta}^{d}=0$. The simulations for generating vibration control plots are carried out for the period of $6 \mathrm{~s}$. For the simulation purpose, the weight of the TA is taken as $5 \%$ of the manipulator weight. For comparing the results depicting vibration attenuation, dual subsystem simulink blocks for manipulator dynamics are created. One block is developed without the control system and the other with the control system. The inputs for the manipulator dynamics are the sinusoidal signal and the Coulomb friction which is nonlinear in nature as stated in (44). The frequency value associated with the simulation is set to $300 \mathrm{rad} / \mathrm{s}$. The acceleration signals generated from the manipulator dynamics blocks are fed to the series of numerical integrators to extract velocity signals and position signals respectively. Overall four tests are performed in Simulink: 1) PD control, 2) PID control, 3) T1-F-PID control and 4) T2-F-PID control. For T1-FPID control, the integrated type-1 fuzzy toolbox for Matlab/Simulink is utilized, whereas for T2-F-PID control, the open source type- 2 fuzzy toolbox ${ }^{[46]}$ is utilized for accomplishing fuzzy techniques. The generated control signals from the controller block is transmitted to TA for the vibration control in the manipulator. The inputs: position error and velocity error, are considered to be Gaussian membership functions. Four membership functions are allocated for position error whereas three membership functions are allocated for velocity error. Normalization is set as $[-1,1]$. The type- 2 fuzzy system is defuzzified using the Karnik-Mendel technique ${ }^{[32]}$. For the type-2 fuzzy system, six IF-THEN rules are sufficient to maintain the regulation error. Ten IF-THEN rules suffice for the maintenance of minimal regulation error in the case of type- 1 fuzzy systems. The technique of Gaussian functions is introduced for type- 1 fuzzy logic. Both type1 /type- 2 fuzzy systems are based on IF-THEN rules illustrated by:

$$
\begin{aligned}
& \text { If } \theta \text { is } \Psi_{1} \text { and } \dot{\theta} \text { is } \Psi_{2} \\
& \text { Then } u_{\theta} \text { is } \Psi_{3}
\end{aligned}
$$

where $\theta$ is the position error, $\dot{\theta}$ is the velocity error, and $u_{\theta}$ is the required control force. $\Psi_{1}, \Psi_{2}$, and $\Psi_{3}$ are the fuzzy sets. The design parameters are $\frac{\eta_{1}}{t_{1}}=\frac{\eta_{2}}{t_{2}}=8$. From Theorem 1, it is evident that the ranges of the gains can be identified. So, based on the ranges of PID gains and substituting the parameters from Table 1 to (25), the following ranges of gains are extracted:

$$
\lambda_{m}\left(K_{p}\right) \geq 219, \lambda_{m}\left(K_{d}\right) \geq 69, \lambda_{M}\left(K_{i}\right) \leq 2500 .
$$


After attempting several trials with the gains based on (47), it is observed that for PD, PID, T1-F-PID and T2F-PID controller, the most suited gains for efficient vibration attenuation as well as stability are

$$
\lambda_{\min }\left(K_{p}\right)=273, \lambda_{m}\left(K_{d}\right)=81, \lambda_{M}\left(K_{i}\right)=1690 .
$$

Also, some tests were carried out by selecting the values from the ranges different from the ones extracted by the Theorem 1. For validation, we selected the gains from the ranges: proportional gain less than 219, derivative gain less than 69 and proportional gain greater than 2500 . It is observed that for each and every test with the increasing gains from that zone, the results were unstable adding more vibration to the manipulator. So, all the result were discarded from the unstable zones.

To validate the performance of the controllers, the vibration attenuation comparisons are carried out among PD, PID, T1-F-PID and T2-F-PID controllers which are displayed in Figs.9-12. The outcomes of the average vibration attenuation is computed by implementing mean squared error illustrated as $M S E=\frac{1}{d a t} \sum_{k=1}^{d} \theta(k)^{2}$, where the chatter vibration is depicted by $\theta(k)$. The total data is illustrated by dat. The data of the average vibration attenuation is shown in Table 2 .

From Table 2, it is validated that T2-F-PID is the superior among all the controllers in vibration attenuation. Fig. 13 depicts the control signal plot of T2-F-PID controller. In Fig. 14, the plot of TA control force is illustrated.

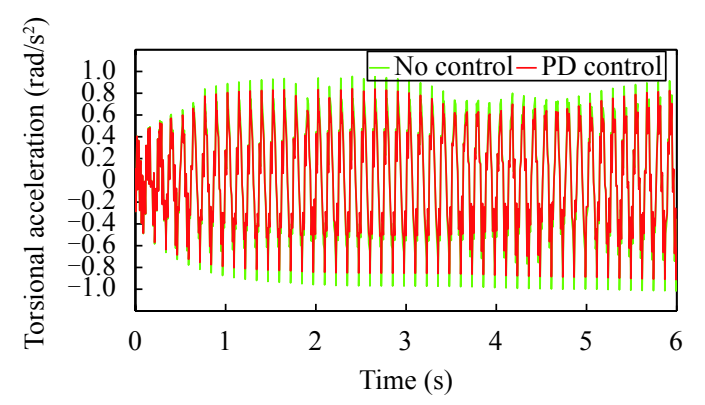

Fig. 9 Manipulator vibration control using PD controller

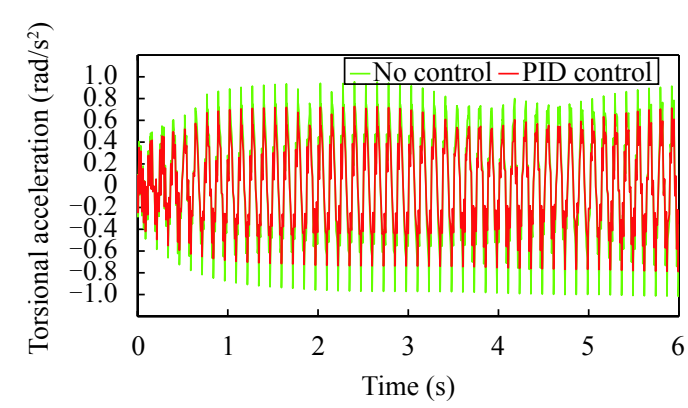

Fig. 10 Manipulator vibration control using PID controller

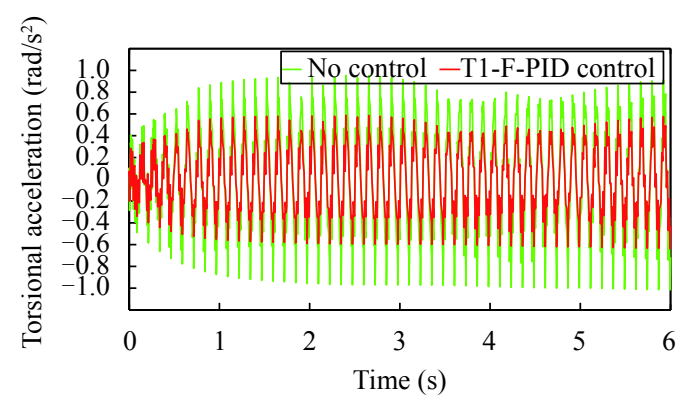

Fig. 11 Manipulator vibration control using T1-F-PID controller

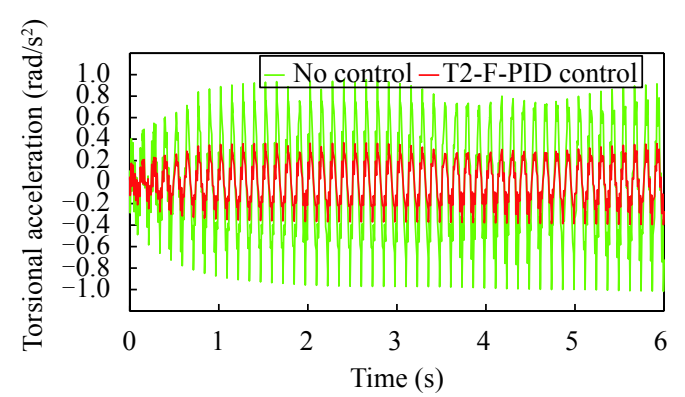

Fig. 12 Manipulator vibration control using T2-F-PID controller

Table 2

\begin{tabular}{ccccc}
\hline No control & PD & PID & T1-F-PID & T2-F-PID \\
\hline 0.6505 & 0.5010 & 0.4113 & 0.1763 & 0.0998 \\
\hline
\end{tabular}

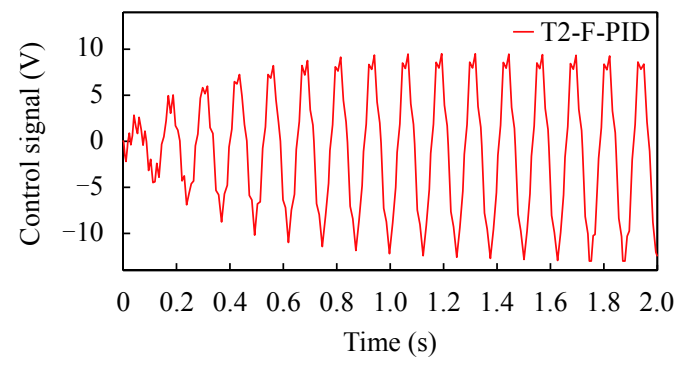

Fig. 13 T2-F-PID control signal

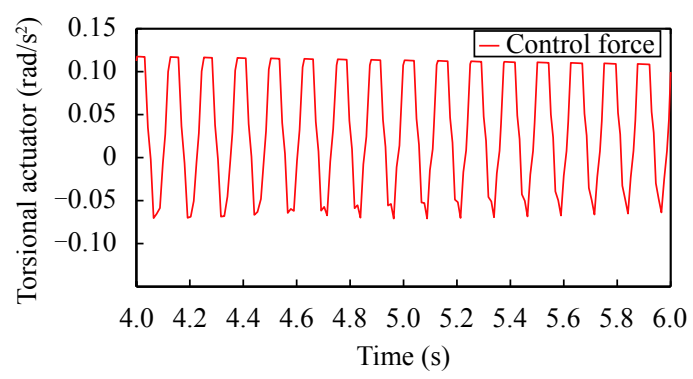

Fig. 14 Torsional actuator control force

\section{Conclusion and future work}

In this work, the stabilization and the control of the 
vibration related to the mechanical manipulator arm is verified and validated, when the present configuration is meant to be automated as needed for agricultural applications \& tasks. The camera setup, when mounted with such motorized arms, will incur tremendous vibrations. This sort of vibration hinders the quality of the acquired data. To minimize such effect, we propose an vibration control approach that uses PID controller in combination with the type-2 fuzzy logic (T2-F-PID). The PID controller produces the key control operation, while the nonlinear compensation is dealt with by means of the fuzzy logic of type-2. For active vibration control, the torsion actuator (TA) movement is simulated. The result obtained by the simulation of T2-F-PID is compared with both a simple PD/PID controller and T1-F-PID controller. The consequence of the study validates that T2 F-PID is the best of all the controllers in achieving proper vibration attenuation. The future work is intended towards the effective design of TA for better efficiency. Also, we aim to compare the effectiveness of T2-F-PID with sliding mode controllers (SMC).

\section{Acknowledgements}

The authors are thankful to Orebro University for reference of the logistics as a part of this study.

\section{Open Access}

This article is licensed under a Creative Commons Attribution 4.0 International License, which permits use, sharing, adaptation, distribution and reproduction in any medium or format, as long as you give appropriate credit to the original author(s) and the source, provide a link to the Creative Commons licence, and indicate if changes were made.

The images or other third party material in this article are included in the article's Creative Commons licence, unless indicated otherwise in a credit line to the material. If material is not included in the article's Creative Commons licence and your intended use is not permitted by statutory regulation or exceeds the permitted use, you will need to obtain permission directly from the copyright holder.

To view a copy of this licence, visit http://creativecommons.org/licenses/by/4.0/.

\section{References}

[1] D. W. Ehrhardt, W. B. Frommer. New technologies for 21st century plant science. The Plant Cell, vol.24, no. 2, pp. 374-394, 2012. DOI: 10.1105/tpc.111.093302.

[2] Growbox.[Online], Available: https://growbox.ch/.

[3] FarmBot.[Online], Available: https://farm.bot/.

[4] M. E. Barrasso. Autonomous Plant Growing Systems, U.S. Patent 20160371830, December 2016.
[5] Sweden's Testbed in AI and autonomous systems, [Online], Available: http://platformaimee.se/?p=1031.

[6] A. Arunachalam, H. Andreasson. RaspberryPi-Arduino (RPA) powered smart mirrored and reconfigurable IoT facility for plant science research. Internet Technology Letters, to be published. DOI: 10.1002/itl2.272.

[7] L. Li, Q. Zhang, D. F. Huang. A review of imaging techniques for plant phenotyping. Sensors, vol.14, no.11, pp. 20078-20111, 2014. DOI: 10.3390/s141120078.

[8] S. Sakurai, H. Uchiyama, A. Shimada, D. Arita, R. I. Taniguchi. Two-step transfer learning for semantic plant segmentation. In Proceedings of the 7 th International Conference on Pattern Recognition Applications and Methods, Funchal, Portugal, pp.332-339, 2018.

[9] S. Sakurai, H. Uchiyama, A. Shimada, R. I. Taniguchi. Plant growth prediction using convolutional LSTM. In Proceedings of the 14th International Joint Conference on Computer Vision, Imaging and Computer Graphics Theory and Applications, Funchal, Portugal, pp.105-113, 2019.

[10] R. R. Shamshiri, C. Weltzien, I. A. Hameed, I. J. Yule, T. E. Grift, S. K. Balasundram, L. Pitonakova, D. Ahmad, G. Chowdhary. Research and development in agricultural robotics: A perspective of digital farming. International Journal of Agricultural and Biological Engineering, vol. 11, no. 4, pp.1-14, 2018. DOI: 10.25165/j.ijabe.20181104.4278.

[11] A. Roshanianfard, N. Noguchi, T. Kamata. Design and performance of a robotic arm for farm use. International Journal of Agricultural and Biological Engineering, vol. 12, no.1, pp.146-158, 2019. DOI: 10.25165/j.ijabe.20191201. 3721 .

[12] Robotics - Introduction. [Online], Available: http://www. site.uottawa.ca/ petriu/CEG4392-IntroRobotics-Arms. pdf.

[13] T. Oh, J. Park, K. Seshadrinathan, S. Lee, A. C. Bovik. No-reference sharpness assessment of camera-shaken images by analysis of spectral structure. IEEE Transactions on Image Processing, vol.23, no. 12, pp.5428-5439, 2014. DOI: $10.1109 /$ TIP.2014.2364925.

[14] M. T. Nguyen, C. Yuan, J. H. Huang. Kinematic analysis of A 6-DOF robotic arm. In Proceedings of the 15th IFToMM World Congress on Mechanism and Machine Science, T. Uhl, Ed., Cham, Germany: Springer, pp. 2965-2974, 2019. DOI: 10.1007/978-3-030-201319_292.

[15] G. Leugering. Control and stabilization of a flexible robot arm. Dynamics and Stability of Systems, vol.5, no.1, pp. 37-46, 1990. DOI: 10.1080/02681119008806082.

[16] S. N. Singh. Control and stabilization of nonlinear uncertain elastic robotic arm. IEEE Transactions on Aerospace and Electronic Systems, vol.24, no.2, pp.148-155, 1988. DOI: $10.1109 / 7.1048$.

[17] V. Etxebarria, A. Sanz, I. Lizarraga. Control of a lightweight flexible robotic arm using sliding modes. International Journal of Advanced Robotic Systems, vol.2, no. 2, pp. 103-110, 2005. DOI: 10.5772/5798.

[18] F. F. Khalil, E. F. Khalil. Stabilization of an inverted robot arm using neuro-controller. Journal of Engineering and Development, vol. 17, no. 3, pp. 183-198, 2013.

[19] W. He, Y. C. Ouyang, J. Hong. Vibration control of a flexible robotic manipulator in the presence of input deadzone. IEEE Transactions on Industrial Informatics, vol. 13, no. 1, 
pp. 48-59, 2017. DOI: 10.1109/T II .2016.2608739.

[20] Z. C. Qiu. Adaptive nonlinear vibration control of a Cartesian flexible manipulator driven by a ballscrew mechanism. Mechanical Systems and Signal Processing, vol. 30, pp. 248-266, 2012. DOI: 10.1016/j.ymssp.2012.01. 002 .

[21] J. J. Wei, Z. C. Qiu, J. D. Han, Y. C. Wang. Experimental comparison research on active vibration control for flexible piezoelectric manipulator using fuzzy controller. Journal of Intelligent and Robotic Systems, vol.59, no.1, pp. 31-56, 2010. DOI: 10.1007/s10846-009-9390-2.

[22] Z. J. Liu, J. K. Liu. Dynamic modeling and vibration control for a nonlinear three-dimensional flexible manipulator. PDE Modeling and Boundary Control for Flexible Mechanical System, Z. J. Liu, J. K. Liu, Eds., Singapore, Springer, 2020. DOI: 10.1007/978-981-15-2596-4_9.

[23] S. Yavuz, M. L. Karagulle. Vibration control of a singlelink flexible composite manipulator. Composite Structures, vol.140, pp.684-691, 2016. DOI: 10.1016/j.com pstruct.2016.01.037.

[24] H. Matsumori, M. C. Deng, Y. Noge. An operator-based nonlinear vibration control system using a flexible arm with shape memory alloy. International Journal of Automation and Computing, vol.17, no.1, pp.139-150, 2020. DOI: $10.1007 / \mathrm{s} 11633-018-1149-4$.

[25] W. Deng, H. L. Liu, J. J. Xu, H. M. Zhao, Y. J. Song. An improved quantum-inspired differential evolution algorithm for deep belief network. IEEE Transactions on Instrumentation and Measurement, vol.69, no.10, pp. 7319-7327, 2020. DOI: 10.1109/TIM.2020.2983233.

[26] S. C. Tong, X. Min, Y. X. Li. Observer-based adaptive fuzzy tracking control for strict-feedback nonlinear systems with unknown control gain functions. IEEE Transactions on Cybernetics, vol.50, no.9, pp.3903-3913, 2020. DOI: 10.1109/TCYB.2020.2977175.

[27] S. C. Tong, Y. M. Li. Robust adaptive fuzzy backstepping output feedback tracking control for nonlinear system with dynamic uncertainties. Science China Information Sciences, vol. 53, no. 2, pp. 307-324, 2010. DOI: 10.1007/s11432010-0031-y.

[28] F. C. Liu, L. H. Liang, J. J. Gao. Fuzzy PID control of space manipulator for both ground alignment and space applications. International Journal of Automation and Computing, vol.11, no. 4, pp. 353-360, 2014. DOI: 10.1007/ s11633-014-0800-y.

[29] K. M. Goher, S. O. Fadlallah. Control of a two-wheeled machine with two-directions handling mechanism using $\mathrm{PID}$ and PD-FLC algorithms. International Journal of Automation and Computing, vol.16, no.4, pp.511-533, 2019. DOI: $10.1007 / \mathrm{s} 11633-019-1172-0$.

[30] R. I. John, P. R. Innocent, M. R. Barnes. Neuro-fuzzy clustering of radiographic tibia image data using type 2 fuzzy sets. Information Sciences, vol.125, no.1-4, pp.65-82, 2000. DOI: 10.1016/S0020-0255(00)00009-8.

[31] J. M. Mendel. Uncertain Rule-based Fuzzy Logic Systems: Introduction and New Directions, Upper Saddle River, USA: Prentice Hall PTR, 2001.

[32] Q. L. Liang, J. M. Mendel. Interval type-2 fuzzy logic systems: Theory and design. IEEE Transactions on Fuzzy Systems, vol.8, no.5, pp.535-550, 2000. DOI: 10.1109/ 91.873577 .

[33] R. Sepulveda, O. Castillo, P. Melin, A. Rodriguez-Diaz, O. Montiel. Experimental study of intelligent controllers un- der uncertainty using type- 1 and type- 2 fuzzy logic. Information Sciences, vol.177, no.10, pp.2023-2048, 2007. DOI: $10.1016 /$ j.ins.2006.10.004.

[34] S. Paul, W. Yu, X. O. Li. Bidirectional active control of structures with type-2 fuzzy PD and PID. International Journal of Systems Science, vol.49, no.4, pp.766-782, 2018. DOI: $10.1080 / 00207721.2017 .1421724$.

[35] K. A. Naik, C. P. Gupta. Performance comparison of type1 and type-2 fuzzy logic systems. In Proceedings of the 4 th International Conference on Signal Processing, Computing and Control, IEEE, Solan, India, pp. 72-76, 2017. DOI: 10.1109/ISPCC.2017.8269652.

[36] Y. Bai, D. L. Wang. On the comparison of type 1 and interval type 2 fuzzy logic controllers used in a laser tracking system. IFAC-PapersOnLine, vol. 51, no. 11, pp. 15481553, 2018. DOI: 10.1016/j.ifacol.2018.08.276.

[37] D. Sun, Q. F. Liao, X. Y. Gu, C. S. Li, H. L. Ren. Multilateral teleoperation with new cooperative structure based on reconfigurable robots and type-2 fuzzy logic. IEEE Transactions on Cybernetics, vol.49, no. 8, pp.2845-2859, 2019. DOI: 10.1109/TCYB.2018.2828503.

[38] S. Paul, A. Arunachalam, D. Khodadad, O. Rubanenko. Fuzzy tuned PID controller for vibration control of agricultural manipulator. In Proceedings of International Congress on Human-Computer Interaction, Optimization and Robotic Applications, IEEE, Ankara, Turkey, 2020. DOI: 10.1109/HORA49412.2020.9152848.

[39] Franka Emika Robot.[Online], Available: https://www. franka.de/.

[40] S. Varde, M. S. Panse. Offline stereo camera calibration of raspberry pi compute module. International Journal of Latest Technology in Engineering, Management \& Applied Science, vol. VI, no. IX, no. 17-20, 2017.

[41] C. Roldan, F. J. Campa, O. Altuzarra, E. Amezua. Automatic identification of the inertia and friction of an electromechanical actuator. New Advances in Mechanisms, Transmissions and Applications, Dordrecht, Netherlands: Springer, pp.409-416, 2014. DOI: 10.1007/978-94-0077485-8_50.

[42] O. Castillo, L. Aguilar, N. Cazarez, P. Melin. Systematic design of a stable type-2 fuzzy logic controller. Forging New Frontiers: Fuzzy Pioneers II, M. Nikravesh, J. Kacprzyk, L. A. Zadeh, Eds., Berlin, Germany: Springer, pp. 319-331, 2008. DOI: 10.1007/978-3-540-73185-6_14.

[43] T. C. Lin, H. L. Liu, M. J. Kuo. Direct adaptive interval type-2 fuzzy control of multivariable nonlinear systems. Engineering Applications of Artificial Intelligence, vol. 22, no. 3, pp.420-430, 2009. DOI: 10.1016/j.engappai.2008. 10.024 .

[44] M. Hassan, R. Dubay, C. Li, R. Wang. Active vibration control of a flexible one-link manipulator using a multivariable predictive controller. Mechatronics, vol.17, no. 6 , pp.311-323, 2007. DOI: 10.1016/j.mechatronics. 2007.02.004.

[45] J. O. Jang, G. J. Jeon. A parallel neuro-controller for DC motors containing nonlinear friction. Neurocomputing, vol.30, no.1-4, pp.233-248, 2000. DOI: 10.1016/S09252312(99)00128-9.

[46] A. Taskin, T. Kumbasar. An open source matlab/simulink toolbox for interval type-2 fuzzy logic systems. In Proceedings of IEEE Symposium Series on Computational Intelligence, IEEE, Cape Town, South Africa, pp.15611568, 2015. DOI: 10.1109/SSCI.2015.220. 


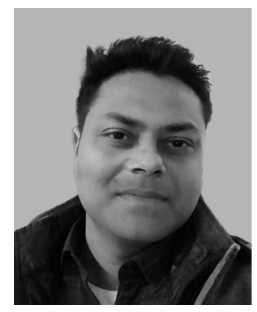

Satyam Paul received the B. Eng. degree in mechanical engineering from National Institute of Technology, India in 2005. He received the M. Eng. degree in mechatronics from VIT University, India in 2009. He received the $\mathrm{Ph}$. D. degree in automatic control from Department of Automatic Control, Center for Research and Advanced Studies of the National Polytechnic Institute (CINVESTAV-IPN), Mexico in 2017. From February 2018 to October 2018, he was a postdoctoral researcher at Tecnologico De Monterrey (ITESM), Mexico. From November 2018 to February 2020, he was a postdoctoral researcher at Department of Mechanical Engineering, Orebro University, Sweden. He has 5 years of teaching experience in the Department of Mechanical Engineering which includes universities from India and Sweden. Currently, he is a lecturer of mechatronics in Department of Engineering Design and in Mathematics, University of the West of England, UK.

His research interests include control systems, vibration control, stability analysis, fault detection and mechatronics.

E-mail: satyam.paul@uwe.ac.uk (Corresponding author)

ORCID iD: 0000-0003-4720-0897

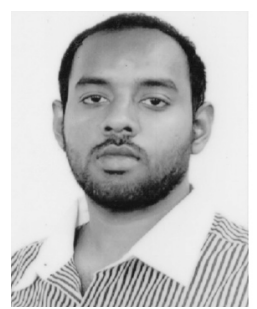

Ajay Arunachalam received the M. Eng. degree in computer science \& engineering from Anna University, India in 2009. He received the $\mathrm{Ph}$. D. degree in computer science and information systems (CSIS) from National Institute of Development Administration (NIDA), Thailand in 2016, with specialization in distributed systems and wireless networks. Prior, to his current role, he was working as Data Scientist at True Corporation Public Company Ltd., Thailand, an Communications Conglomerate, working with Petabytes of data, building \& deploying deep models in production. He is a researcher in artificial intelligence at Centre for Applied Autonomous Sensor Systems (AASS), School of Science and Technology, Orebro University, Sweden. Currently, he is a part of the Food \& Health Program at the university to which he contributes with the research on Autonomous Precision Agricultural Robot. The goal is smart food production \& logistics supported by artificial intelligence.

His research interests include opacity in artificial intelligence (AI) systems, machine learning, optimization, big data, algorithmic trading, natural language processing, and distributed systems \& wireless networks.

E-mail: ajay.arunachalam@oru.se

ORCID iD: 0000-0003-1827-9698

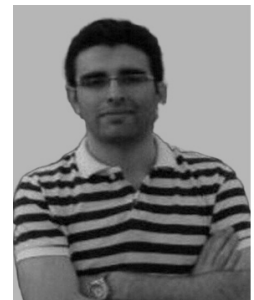

Davood Khodadad received the B.Sc. degree in electrical engineering concentrating on biomedical imaging systems from Sahand University of Technology, Iran in 2008. He received the M. Sc. degree in bioelectronics from Tehran University of Medical Sciences, Iran in 2011. He received the Ph. D. degree in experimental mechanics from Lulea University of Technology, Sweden in 2016, where he focused on the development of multispectral and dual-polarization digital holography for threedimensional imaging applied for geometry and quality control purposes. He was a post-doctoral research fellow in Waves, Signals and Systems Research Group, Linnaeus University, Sweden to focus on the development of electrical impedance tomography (EIT) and diffusion-based optical tomography to be applied in neonatal intensive care units (NICU) during the years 2016-2018. This background led to his employment at Orebro University as an associate senior lecturer until March 2020. At Orebro University, he worked on X-ray tomographic (CT) methods in order to improve image quality and apply micro CT scan for designing stronger internal structures in complex products as well as to non-destructive methods for verification of e.g., additively manufactured (AM) products. He left Orebro University when recruited to Umea University as an associate professor at the Department of Applied Physics and Electronics. Currently, he is an associate professor at Department of Applied Physics and Electronics, Umea University, Sweden.

His research interests include digital holography, imaging systems, speckle metrology and optical metrology.

E-mail: davood.khodadad@umu.se

ORCID iD: 0000-0003-2960-3094

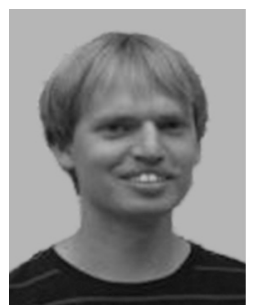

Henrik Andreasson received the M. Sc. degree in mechatronics from the Royal Institute of Technology (KTH), Sweden in 2001 , and the $\mathrm{Ph} . \mathrm{D}$. degree in computer science from Orebro University, Sweden in 2008. He is currently an associate professor with Center for Applied Autonomous Sensor Systems (AASS), School of Science and Technology, Orebro University, Sweden.

His research interests include mobile robotics, computer vision, and machine learning.

E-mail: henrik.andreasson@oru.se

ORCID iD: 0000-0002-2953-1564

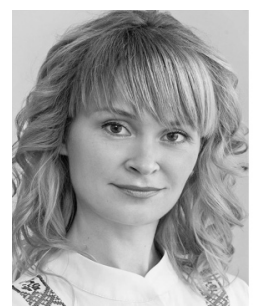

Olena Rubanenko received the B. Eng degree and the M. Sc. degrees in electrical systems and networks from Vinnytsia National Technical University, Ukraine in 2006 and 2007. She received the Ph. D. degree from Department of Electric Systems and Stations, Vinnitsya National Technical University, Ukraine in 2011. She is a researcher in Department of Electric Systems and Stations at the Vinnitsya National Technical University, Ukraine. After that, she was a doctoral student in electric stations, networks, and systems at Vinnytsia National Technical University, Ukraine. From April 2019 to December 2020, she was a postdoctoral researcher of a Regional Innovational Center, Faculty of Electrical Engineering, University of West Bohemia in Pilsen, Czech Republic. She has 9 years of teaching experience in Department of Electric Systems and Stations, Vinnitsya National Technical University, Ukraine.

Her research interests include renewable energy sources, power control, neuro fuzzy modeling and machine learning.

E-mail: rubanenk@rice.zcu.cz

ORCID iD: 0000-0002-2660-182X 